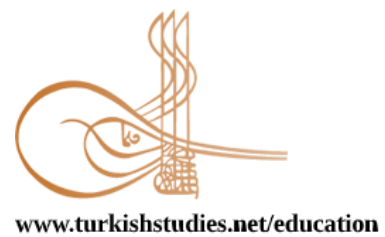

Turkish Studies - Educational Sciences

www.turkishstudies.net/education

eISSN: 2667-5609

Research Article / Araștırma Makalesi

\title{
Müzik Öğretmeni Yetiştiren Kurumlarda Orkestra/Oda Müziği Eğitim Sürecinin Öğretim Elemanları Görüşleri Doğrultusunda İncelenmesi *
}

\author{
Investigation of Orchestra / Chamber Music Education Process in Line with the Views of \\ Instructors in Institutions Training Music Teachers
}

\author{
Mustafa Gök $^{* *}$ - Mehmet Can Çiftçibaşı ${ }^{* * *}$
}

\begin{abstract}
This research aims to examine the education process of the orchestra / chamber music lesson in institutions training music teachers. In line with this purpose, the findings in the planning, implementation and evaluation processes of the course were examined and similarities and differences were tried to be revealed based on the opinions of the instructors who conducted the course. The research is a survey study, which is one of the descriptive research types. In order to achieve the targeted objectives of the research, after the related literature review, data collection tool was prepared by seeking expert opinions. The data collection tool consists of a standardized open-ended interview form. The study group of the research consists of the instructors who conduct orchestra / chamber music lessons in 9 different universities in the department of music education. The research was limited to the data in the 2018-2019 academic year. Findings obtained by using data collection tool were analyzed by content analysis method. According to the results obtained in the research, it was determined that the instructors pay attention to the quality of the works, the technical readiness of the students and their goals and objectives while determining the work to be played by the student. Another surprising result, which has been found to affect the education process negatively, is the inadequacy of the physical conditions and course hours. It is an another result that there are differences between the universities in the types and periods of the works studied within the scope of the course. In line with the results obtained, suggestions were made, which are thought to contribute to the orchestra / chamber music lesson education process and to minimize the experienced negativities.
\end{abstract}

Structured Abstract: The aim of this research is to reveal the differences and similarities by examining the findings related to the planning, implementation and evaluation stages of the course in line with the opinions of the orchestra / chamber music course instructors in institutions training music teachers. In forming the

\footnotetext{
* $\mathrm{Bu}$ çalışma "Müzik Öğretmeni Yetiştiren Kurumlarda Orkestra/Oda Müziği Eğitim Sürecinin Öğretim Elemanları Görüşleri Doğrultusunda İncelenmesi” başlıklı yüksek lisans tezinden derlenmiştir.

** Yüksek Lisans Öğrencisi, Burdur Mehmet Akif Ersoy Üniversitesi, Eğitim Bilimler Enstitüsü

Graduate Student, Burdur Mehmet Akif Ersoy University, Institu of of Education Sciences

ORCID 0000-0001-6498-7906

mg.mustafagok@gmail.com

**** Dr. Öğr. Üyesi, Burdur Mehmet Akif Ersoy Üniversitesi, Eğitim Fakültesi, Güzel Sanatlar Eğitimi Bölümü

Asst. Prof. Dr. Burdur Mehmet Akif Ersoy University, Faculty of Education, Education of Fine Arts

ORCID 0000-0002-8825-1001

mcciftcibasi@mehmetakif.edu.tr

Cite as/ Atıf: Gök, M. \& Çiftçibaşı, M. C. (2020). Müzik öğretmeni yetiştiren kurumlarda orkestra/oda müziği eğitim sürecinin öğretim elemanları görüşleri doğrultusunda incelenmesi. Turkish Studies - Education, 15(3), 1675-1691. https://dx.doi.org/10.29228/TurkishStudies.41859

Received/Geliş: 19 February/Şubat 2020

Accepted/Kabul: 21 June/Haziran 2020

Checked by plagiarism software

Copyright (C) INTAC LTD, Turkey

Published/Yaym: 25 June/Haziran 2020

CC BY-NC 4.0
} 
subject of the research programs and music teacher training institutions in Turkey along with all of the different names of course to play. Orchestra / Chamber Music lesson with its current name is the focus of many researchers. Since there is no lesson in orchestral conducting in the Music Education Undergraduate Programs, orchestra / chamber music lessons are generally conducted by string instrument instructors. It is observed that the orchestra / chamber music lessons show differences among the departments in terms of their being conducted by different educators, the different opportunities provided by the departments, cultural differences and student levels. From this point of view, it is thought that it would be beneficial to examine the orchestra / chamber music education process in line with the opinions of the instructors.

Research is a descriptive study using qualitative research methods. In order to base the research and reach the targeted objectives, the resources related to the subject were examined and the data collection tool was prepared by getting expert opinions. The standardized open-ended interview form to be used in the research was prepared by taking the opinions of expert trainers. The standardized open-ended interview form consists of two parts. In the first part, the questions including the demographic information of the lecturers are included, and in the second part, the questions related to the stages of planning, implementation and evaluation of orchestra / chamber music education and the creation of the orchestra repertoire are included. During the preparation phase of the standardized open-ended interview form, data collection tools used in similar studies were examined and expert opinions were received and finalized. The study group of the study was Burdur Mehmet Akif Ersoy University (MAKU), Muğla Sitkı Koçman University (MSKU), Gazi University (GU), Harran University (HU), Karadeniz Technical University (KTU), Ondokuz Mayıs University (OMU), Pamukkale University (PAU ), Balikesir University (BAUN) and Bolu Abant Izzet Baysal University (AIBU) are teaching staff who conduct orchestra / chamber music lessons in 2018-2019 academic year. The data obtained from the interviews with the lecturers were transferred to the computer environment in written text. Content analysis was conducted to be used in related sub-problems and interviews were categorized under certain headings. Multiple interviewer responses can be found in the codes in the themes. The coding system was used for each interviewer. The work lists coming from the lecturers were preserved exactly with the information in the interview form and turned into a table. Since the research was carried out primarily for the purpose of determining which works are being studied, the frequency and percentage values are not given depending on the frequency of use of the works, but are presented only in a list.

It was observed that the instructors of the Department of Music Education Orchestra / Chamber Music course pay attention to the student levels, the quality of the works, the concert goals and objectives for choice of works. It is also among the results that faculty members consider cultural values and find it important to choose works that will be appreciated by the audience. It has been observed that faculty members are faced with problems such as insufficient resources, low instrument levels and uneven distribution of the instruments in the orchestra while planning the works to be run. Other conclusions are that the works that faculty members want to study cannot reach orchestral arrangements from time to time, find the written sources insufficient, and that they do not find some of the works they reach at the grade in accordance with student levels. Due to the differences in the levels of the students in the orchestra and the imbalances in the distribution of the instruments, it was obtained that technically difficult works were also not repertoured. It was concluded that this situation compelled the academic staff during the selection process. It has been observed that faculty members face problems such as lack of time for students to attend classes in the education-teaching process and their level of readiness is not sufficient, insufficient physical conditions and less class hours. It is also stated that there are problems arising from the fact that the students in the orchestra have low quality fabricated instruments and the students do not show enough interest in the orchestra lesson. Concerning the solution of the problems arising from the students during the orchestra education process, it was concluded that the faculty members cooperate with the individual instrument instructors and request assistance from the instructors. Some of the other results are that some lecturers use phone applications (WhatsApp etc.), do their homework and daily work with these applications, and an academician encourages students to solo performances and concerts. It has been determined that the most used methods in the course are show-off method, group work and individual listening method. These three methods are the most used, productive and considered to be important for achieving orchestral lesson target achievements in musical instrument and orchestra education. The instructors stated that the techniques of drill, legato, pizzicato are always used in the lessons, staccato, portato, martele techniques are frequently used, spiccato, sautille techniques are used moderately, colle, saltando, drill porte, col legno battuo and chopping techniques are used very little. During the evaluation phase, it was determined that some of the instructors used the scale and some did not use the scale. In the evaluation, it is seen that they have different criteria (attendance, observation form, 
1 minute tuning, etc.). In line with the findings, it was determined that the lecturers used individual, small groups and the whole orchestra listening methods for evaluation. In this process, it has been observed that there are faculty members who meet with other instrumental teachers and conduct written exams. It is seen that there are differences in the types and periods of the works studied in the orchestra / chamber music lesson. It is concluded that the works of A.Vivaldi, which are among the classical music composers, are mostly included, and other composers whose works are frequently used are W.A.Mozart, J.Haydn, P.I.Tchaikovsky, J.S.Bach, H.Purcell and E.Grieg. It has been determined that the works of Turkish composers and polyphonic arrangements of Turkish music works are frequently used in orchestra / chamber music lesson. It was observed that the compositions and arrangements of E. Tuğcular and O. Balcı's arrangements were frequently worked. In addition to these works, it has been determined that music types such as popular music and film-series music are used in orchestra / chamber music lesson.

Musical choices in the departments of music education can be made by considering the numerical balance of the instrument groups that form the orchestra during the orchestra / chamber music education process. The number of works and arrangements suitable for the level can be increased, and written sources can be enriched for student orchestras of music education departments. During the orchestra / chamber music lesson, students can get help from their individual instrument teachers, and this method can help students overcome technical difficulties more easily. Orchestra workspaces can be physically made more suitable.

Keywods: Music, Music Teaching, Instructor Opinions, Orchestra, Repertoire

Öz: $\mathrm{Bu}$ araştırma, müzik öğretmeni yetiştiren kurumlardaki orkestra/oda müziği dersinin eğitim sürecini incelemeyi amaçlamaktadır. Bu amaç doğrultusunda dersi yürüten öğretim elemanlarının görüşlerinden yola çıkılarak dersin planlama, uygulama ve değerlendirme süreçlerindeki bulgular incelenmiş, benzerlik ve farklılıklar ortaya konulmaya çalışılmıştır. Araştırma, betimsel araştırma türlerinden tarama çalışması niteliğindedir. Araştırmanın hedeflenen amaçlara ulaşılabilmesini sağlamak için ilgili literatür taraması yapıldıktan sonra uzman görüşlerine başvurularak veri toplama aracı hazırlanmıştır. Veri toplama aracı, standartlaştırılmış açık uçlu görüşme formundan oluşmaktadır. Araştırmanın çalışma grubunu, 9 farklı üniversitenin müzik eğitimi anabilim dalında, orkestra/oda müziği derslerini yürüten öğretim elemanları oluşturmaktadır. Araştırma 2018-2019 eğitim- öğretim yılındaki veriler ile sınırlı tutulmuştur. Araştırmada standartlaştırılmış açık uçlu görüşme formu kullanılmıştır. Veri toplama aracı kullanılarak elde edilen bulgular içerik analizi yöntemiyle çözümlenmiştir. Araştırmada ulaşılan sonuçlara göre, öğretim elemanlarının öğrencinin çalacağı eseri belirlerken, eserlerin niteliğine, öğrencilerin teknik hazırbulunuşluğuna ve konser amaç ile hedeflerine dikkat ettikleri belirlenmiştir. Eğitim-öğretim sürecini olumsuz yönde etkilediği tespit edilen bir diğer çarpıcı sonuç ise ders saati ile fiziki şartların yetersizliğidir. Üniversiteler arasında, ders kapsamında çalışılan eserlerin tür ve dönemlerinde farklılıkların olduğu tespit edilen bir diğer sonuçtur. Barok dönem eserlerin ve Türk bestecilerin beste ve düzenlemelerinin sıklıkla kullanıldığı tespit edilmiştir. Elde edilen sonuçlar doğrultusunda, orkestra/oda müziği dersi eğitim sürecine katkı sağlayacağı ve yaşanılan olumsuzlukları azami düzeye indireceği düşünülen önerilerde bulunulmuştur.

Anahtar Kelimeler: Müzik, Müzik Eğitimi, Öğretim Elemanı Görüşleri, Orkestra, Repertuvar

\section{Giriş}

Bireylerin eğitiminin öneminden bahsetmek için insanoğlunun varoluşuna, insanlı̆̆ın kökenine inmek gerekmektedir. Eğitim, kişinin doğumundan ölümüne kadar devam eden, toplumdaki bir birey olma sürecini etkileyen en önemli faktördür. Kişi eğitim sonucunda kendine bir yer, bir kimlik, bir duruş bulur.

"Eğitim, kültürün bir sonraki nesile aktarılmasını sağlayan en etkili yöntemdir. Bireysel ve toplumsal değişim, gelişim ve şekillendirmede önemli ve etkili rol oynayan, doğumdan ölüme kadar devam eden aktif bir süreçtir. Olumlu davranış elde edilemeyen durumlarda, eğitim amacına ulaşamamış demektir" (Yener, 2006: 4). Eğitim, bir davranış değiştirme sürecidir. Eğitim toplumu ve bireyi bilinçlendirme, yönlendirme, değiştirme ve geliştirmede en etkili süreçtir. Çağdaş eğitim ise bilim, sanat ve teknik boyutlarını kapsayan bir çerçevede gerçekleştirilir (Uçan, 1994: 14). 
Müzik eğitimi sanat eğitiminin önemli bir boyutudur. Ülkemizde müzik eğitimcisi yetiştirme sürecinin temelleri Musiki Muallim Mektebi ile atılmıştır. Musiki Muallim Mektebi Türkiye'de müzik eğitimcisi yetiştiren ilk kurumdur. 1924 y1lında kurulmuştur. Ardından 19821998 yılları arasında Gazi Üniversitesi tarafından hazırlanan müzik öğretmenliği lisans programının rol modelliğinde her üniversite kendi programını oluşturmuştur. 1998 yılından itibaren ise merkezi bir program uygulamaya konulmuştur (Özeke, 2003).

Araştırmanın da konusunu oluşturan ve Türkiye'de müzik öğretmeni yetiştiren kurumların bütün programlarında birlikte çalmaya yönelik derslerin farklı isimlerde ve farklı yoğunluklarda yer aldığı görülmektedir. Günümüzdeki ismiyle Orkestra/Oda Müziği dersi birçok araştırmacının odağ1 konumundadır (Öz, 2001; Kıvrak, 2003; Türkmen, 2006; Varış 2007; Delikara 2017; Akyürek 2018; Şen vd. 2019).

“Orkestra/Oda müziği eğitimi dersi, müzik öğretmeni yetiştiren kurumlarda, Oda Müziği/Talebe Orkestrası, Toplu Çalg1 Çalışmaları ve Orkestra, Birlikte Seslendirme, Seçmeli Müzik Özel Alanları gibi çeşitli adlar altında Müzik Eğitimi Programları içinde yer almıştır" (Öz 2001: 94).

YÖK'ün 2007 yılında yayımladığ1 “Öğretmen Yetiştirme ve Eğitim Fakülteleri 19822007” ve 2018 yılında yayımladığ 1 "Müzik Öğretmenliği Lisans Programı" k1lavuzlarına göre orkestra/oda müziği dersi haftalık ders dağılımları aşağıda verilmiştir:

Tablo 1: 1983-2019 Y1lları Arasında Orkestra-Oda Müziği Dersinin Haftalık Ders Saatleri

\begin{tabular}{llcccc}
\hline Yı1 & Ders Adı & 5. Yarıyıl & 6. Yarıyıl & 7. Yarıyıl & 8. Yarıyıl \\
\hline \multirow{2}{*}{$1983-84$} & $\begin{array}{l}\text { Orkestra 1,2,3,4 } \\
\text { Müzik Toplulukları Yönetimi 1,2 }\end{array}$ & $2+2$ & $2+2$ & $2+2$ & $2+2$ \\
$1998-99$ & $\begin{array}{l}\text { Orkestra-Oda Müziği 1,2,3 } \\
\text { Orkestra-Oda Müziği ve Yönetimi }\end{array}$ & $2+2$ & $2+2$ & $2+2$ & 2 \\
$2006-07$ & $\begin{array}{l}\text { Orkestra-Oda Müziği 1,2,3 } \\
\text { Orkestra-Oda Müziği ve Yönetimi }\end{array}$ & $1+2$ & $1+2$ & $1+2$ & $1+2$ \\
$2018-19$ & Orkestra-Oda Müziği 1,2,3,4 & $1+2$ & $1+2$ & $1+2$ & $1+2$ \\
\hline
\end{tabular}

Bu derslerin yanında 1983-1984 yılı haftalık ders saatleri incelendiğinde, III. ve IV. yarıyılda Toplu Çalma I-II derslerinin programda yer aldığg görülmektedir. IV. yarıyıldan itibaren orkestra dersi ana çalgısı piyano ve şan olmayan öğrencilere yönelik açılmıştır.

Orkestra/oda müziği dersi sürecinde toplu çalmaya yönelik davranışların kazandırılması hedeflenmektedir. Bununla birlikte Türk ve dünya müziklerinden seçkin eserler öğretilmektedir. Eserler önce bireysel olarak sonra toplu şekilde çalışılmakta seslendirilmektedir (YÖK, 2006, akt. Akyürek, 2009).

Orkestra/oda müziği dersini yürüten eğitimcilerin öğrencilerin çalgılarındaki teknik düzeyleri hakkında bilgi sahibi olması gerekmektedir. Eğitim-öğretim sürecinde hem öğrencilerin, hem de dinleyicilerin ilgisini çekecek nitelikte bir repertuvar hazırlamak öğretim elemanının sorumluluğundadır. Ulusal ve uluslararası düzeyde seçkin eserlerden oluşan, öğrencilerin hem teknik, hem de müzikal yönden gelişmesini sağlayacak eserlerin seçilmesinin, dersin kazanımlarının gerçekleşmesine olumlu etkilerinin olacağı düşünülmektedir. 'Colson (2012)'a göre herhangi bir enstrümantal müzik topluluğunu yöneten kişinin üç hedefi olmalıdır. Bunlar; uyumlu ve müzikal bir topluluk oluşturmak, enstrüman çalan bireylerin ve topluluğun performansını hem teknik hem de müzikal anlamda geliştirmek, otantik, müzikal ve heyecan verici bir performans için repertuvar hazırlamaktır" (akt. Şen vd., 2019).

Orkestra/oda müziği derslerinin farklı eğitimciler tarafından yürütülmesi, bölümlerin sağladığı imkânların aynı olmaması, kültürel değişiklikler, öğrenci seviyeleri gibi değişkenlerin mevcudiyeti nedeniyle dersin işlenişi bakımından anabilim dalları arasında farklılıklar 
bulunmaktadır. Bu noktadan hareketle orkestra/oda müziği eğitim sürecinin, dersi yürüten öğretim elemanlarının görüşleri doğrultusunda incelenmesinin faydalı olacağı düşünülmüştür. Araştırmada şu sorulara cevap aranmıştır:

1. Müzik öğretmeni yetiştiren kurumlardaki orkestra/oda müziği dersini yürüten öğretim elemanlarının dersin planlanma aşamasına ilişkin görüşleri nelerdir?

2. Müzik öğretmeni yetiştiren kurumlardaki orkestra/oda müziği dersini yürüten öğretim elemanlarının dersin uygulama aşamasına ilişkin görüşleri nelerdir?

3. Müzik öğretmeni yetiştiren kurumlardaki orkestra/oda müziği dersini yürüten öğretim elemanlarının dersin değerlendirme aşamasına ilişkin görüşleri nelerdir?

4. Müzik öğretmeni yetiştiren kurumlardaki orkestra/oda müziği dersinde çalınan eserler (repertuvar) nelerdir?

\section{Yöntem}

$\mathrm{Bu}$ araştırma, betimsel araştırma türlerinden tarama çalışması niteliğindedir. Eğitim alanındaki araştırmalarda en yaygın betimsel yöntem tarama (survey) çalışmasıdır, çünkü araştırmacılar bireylerin, grupların ya da fiziksel ortamların özelliklerini özetlerler (Büyüköztürk vd., 2009: 16). "Tarama araştırmacısı, nesnenin ya da bireyin direkt kendini inceleyebileceği gibi, önceden belgelenmiş çeșitli kayıtlara ve alandaki kaynak kişilere başvurarak, elde edeceği dağınık verileri, kendi gözlemleriyle bir sistematik içerisinde bütünleştirerek yorumlamalıdır" (Karasar, 2009: 77).

Araştırma sürecinde alanyazın incelenmiş, uzman görüşleri alınarak veri toplama aracı oluşturulmuştur. Araştırmada standartlaştırılmış açık uçlu görüşme formu kullanılmıştır. Öğretim elemanlarının cevaplarından oluşan veriler ilgili alt problemlere göre çözümlenmiş ve raporlaştırılmıştır.

\section{Çalıșma Grubu}

Çalışma grubunda yer almakta olan öğretim elemanlarına ait demografik bilgiler Tablo 2'de verilmiştir.

Tablo 2: Çalışma Grubuna İlişkin Demografik Bilgiler

\begin{tabular}{lcccc}
\hline Üniversite & Ünvan & Branş & İş deneyimi & Orkestra Dersi Deneyimi \\
\hline Abant İzzet Baysal & Prof. Dr. & Viyola & $21-25$ & $16-20$ \\
Balıkesir & Doç. Dr. & Viyola & $11-15$ & $6-10$ \\
Gazi & Doç. Dr. & Keman & $16-20$ & $11-15$ \\
Harran & Öğr. Gör. & Viyola & $6-10$ & $6-10$ \\
Karadeniz Teknik & Öğr. Gör. & Keman & $21-25$ & $16-20$ \\
Mehmet Akif Ersoy & Dr. Öğr. Üyesi & Viyolonsel & $11-15$ & $6-10$ \\
Muğla Sitk1 Koçman & Dr. Öğr. Üyesi & Keman & $16-20$ & $16-20$ \\
Muğgla Sitk1 Koçman & Dr. Öğr. Üyesi & Klarnet & $6-10$ & $1-5$ \\
Muğla Sitk1 Koçman & Dr. Öğr. Üyesi & Keman & $16-20$ & $1-5$ \\
Ondokuz Mayıs & Doç. Dr. & Viyola & $21-25$ & $11-15$ \\
Pamukkale & Öğr. Gör. & Viyolonsel & $11-15$ & $6-10$ \\
\hline
\end{tabular}

\section{Veri Toplama Araçları}

Araştırmada veriler standartlaştırılmış açık uçlu görüşme formu kullanılarak toplanmıştır. "Standartlaştırılmış açık uçlu görüşme; dikkatlice yazılmış ve belirli bir sıraya konmuş bir dizi sorudan oluşur ve her görüşülen bireye bu sorular aynı tarz ve sırada sorulur" (Patton, 1987, akt. Yıldırım \& Şimşek, 2006: 123). Görüşme soruları, görüşmenin niteliğine göre değişiklik göstermektedir. Sorular görüşmeden önce hazırlanmalı, konu ve kimlik bilgilerine yönelik olarak 
araştırmayı amacına ulaştıracak sayıda ve özellikte olmalı, gereksiz yere soru sayısı arttırılmamalidır (Karasar, 2014: 168).

Veri toplama aracı iki bölümden oluşmaktadır. Birinci bölümde demografik bilgiler ile ilgili sorular, ikinci bölümde ise orkestra/oda müziği dersinin aşamalarına ilişkin sorulara yer verilmiştir. Alanyazında yer alan benzer araştırmalardaki veri toplama araçları incelenmiş, uzman görüşleri de alınarak veri toplama aracı oluşturulmuştur.

\section{Verilerin Analizi}

Elde edilen verilerin çözümlenmesinde içerik analizi kullanılmıştır. "İçerik analizi metinlerden oluşan kümedeki belirli kelimelerin ya da kavramların varlığını belirlemek amacıyla yapılır. Araştırmacılar bu kelime ile kavramların varlı̆̆ını, ilişki ve anlamlarını belirler, analiz eder ve metinlerdeki mesajlara ilişkin çıkarımlarda bulunurlar" (Büyüköztürk vd., 2009: 263).

İlgili alt problemlerde kullanılmak üzere yazılı metin haline getirilen veriler içerik analizine tabi tutulmuş ve görüşmeler belirli başlıklar altında toplanarak temalar ve kodlar belirlenmiştir. Öğretim elemanlarından gelen eser listeleri, görüşme formundaki bilgileri ile aynen korunarak tablo haline getirilmiştir. Araştırmada, hangi eserlerin çalışıldığının tespitine öncelik verilmesi sebebiyle, eserlerin kullanım sıklığına bağlı olarak frekans ve yüzde değerleri verilmemiş sadece liste halinde sunulmuştur.

\section{Bulgular ve Yorumlar}

Tablo 3: Dersin Planlama Sürecine İlişkin Öğretim Elemanı Görüşlerinin Temaları

\begin{tabular}{|c|c|c|c|c|}
\hline Temalar & Kodlar & Katılımc1 & $\mathrm{f}$ & $\%$ \\
\hline \multirow[t]{8}{*}{ Kriter } & Seviye & $\begin{array}{l}\text { K.1, К.2, К.3, К.4, К.5, К.6, К.7, К.8, К.9, } \\
\text { K.10, К.11 }\end{array}$ & 11 & 100 \\
\hline & Konser içeriği & $\begin{array}{l}\text { К.1, К.2, К.3, К.4, К.5, К.6, К.7, К.8, К.9, } \\
\text { К.10, К.11 }\end{array}$ & 11 & 100 \\
\hline & Eser niteliği & $\begin{array}{l}\text { К.1, К.2, К.3, К.4, К.5, К.6, К.7, К.8, К.9, } \\
\text { К.10, К.11 }\end{array}$ & 11 & 100 \\
\hline & Dinleyici beğenisi & K.1, K.3, K.4, K.5, К.11 & 5 & 45 \\
\hline & Öğrencilerin beğenisi & К.3, К.7, К.9, К.11 & 4 & 36 \\
\hline & Külttürel değerler & K.1, K.8 & 2 & 18 \\
\hline & Çalgı dağılımı & K.2, K.5 & 2 & 18 \\
\hline & $\begin{array}{l}\text { Diğer çalg1 eğitimcilerinin } \\
\text { beklentileri }\end{array}$ & K.4 & 1 & 9 \\
\hline \multirow[t]{3}{*}{ Görüş } & Öğretim elemanı görüşleri & К.2, К.4, К.5, К.6, К.8, К.9, К.10, К.11 & 8 & 72 \\
\hline & Öğrenci görüşleri & К.2, К.3, К.4, К.5, К.7, К.8, К.10 & 7 & 63 \\
\hline & Görüş almıyorum & K.1 & 1 & 9 \\
\hline
\end{tabular}

Tablo 3 incelendiğinde kriter teması altında "seviye", "konser içeriğì", "eser niteliğì", "dinleyici beğenisi”, "öğrencilerin beğenisi", "kültürel değerler", "çalgı dağılımı", "diğer çalg1 eğitimcilerinin beklentileri” olmak üzere 8 kod bulunmaktadır. Öğretim elemanlarının ifadelerinden bazı örnekler aşağıdaki gibidir.

K2: Dersin planlama aşamasında ilk olarak bu dersi alan öğrencilerin çalg1 dağılımları, ardından çalgıdaki performans düzeyleri ve son olarak seçilen repertuvarın evrensel nitelikli örneklerden oluşmasına dikkat edilmesi gelmektedir.

K4: Eğer öncelik orkestra eğitimi ise; konser, etkinlik gibi beklentiler göz önünde bulundurulmadan dersin programına ve hedef kazanımlarına yönelik repertuvar seçilmelidir. Eğer öncelik konser vb. etkinlikler için repertuvar oluşturmak ise de yapılacak olan etkinliğin türü, amacı ve hedef kitlesi baz alınarak repertuvar belirlenmelidir. 
K7: Repertuvar oluştururken ilk önceliğim öğrencilerin çalarken zevk alacağ 1 eserleri seçmeye özen göstermek oluyor. Onların keyif alarak çalacakları ve mutlu olacakları eserleri seçmeye dikkat ediyorum. Ardından teknik ve müzikal anlamda geliştirecek olan eserlere geçiyorum.

K8: Öğrencilerin seviyelerine, eserlerin eğitsel boyutlarına ve niteliklerine, ulusal-evrensel değerlere dikkat ediyorum. Bence repertuvar planlaması yapılırken eserlerin kazanımları ve yapılması planlanan etkinlikler göz önüne alınmalı.

Görüş teması altında "öğretim elemanı görüşleri”, "öğrenci görüşleri”, "görüş almıyorum” olmak üzere 3 kod bulunmaktadır. Öğretim elemanlarının özgün ifadelerinden bazı örnekler aşağıdaki gibidir:

K10: Genellikle hazırladığım programlarda solistlere görev veriyorum. Öğrencilerin bireysel çalg1 öğretmenleriyle görüşüyorum. Öğrencilerin de çalmayı istedikleri eserleri öğreniyorum.

K11: Çoğunlukla bireysel çalgı öğretim elemanına başvurmuyorum. Eğer öğrencilere solo çaldırmayı düşünüyorsam çalacağı esere yönelik bireysel çalgı ögretim elemanına bazen danıştığım oluyor. Bu durum öğrenciyi daha iyi tanıyan bireysel çalgı öğretim elemanından fikir alabilmek adına gerekli olabiliyor.

Elde edilen bulgular doğrultusunda öğretim elemanlarının, planlama sürecinde en fazla öğrenci seviyelerine, konser amaç ve hedeflerine, seçilen eserlerin niteliğine dikkat ettikleri görülmektedir. Orkestrada repertuvar oluşturabilmek için öğrenci seviyelerini göz önünde bulundurmak çok önemli bir husustur. Ayrıca öğrencilerin bireysel çalgı seviyelerinde de ciddi farkl11ıklar olabilmektedir. Orkestra için bestelenmiş evrensel düzeyde kabul gören eserlerde, genellikle öğrencilerin seviyelerini zorlayacak teknik zorluklar bulunmaktadır. Bu sebepten dolayı öğretim elemanlarının eser seçiminde, seviyelere oldukça dikkat ettikleri söylenebilir. Gerçekleştirilmesi planlanan konserlerin ve etkinliklerin içeriğinin de seçilen eserler üzerinde etkili bir belirleyici olduğu görülmektedir. Öğrencilerin çalgı dağglımlarının bazen orkestra yapısı için uygun olmaması sebebiyle eser seçiminde öğretim elemanlarının zorlandığı ve ayrıca üniversitenin bulunduğu yörenin kültürel özelliklerinin de eser seçimini etkilediği söylenebilir. 
Tablo 4: Dersin Eğitim-Öğretim Sürecine İlișkin Öğretim Elemanı Görüşlerinin Temaları

\begin{tabular}{|c|c|c|c|c|}
\hline Temalar & Kodlar & Katılımc1 & $\mathrm{f}$ & $\%$ \\
\hline \multirow{5}{*}{$\begin{array}{l}\text { Kullanılan } \\
\text { yöntemler }\end{array}$} & Gösterip yaptırma & К.1, К.2, К.3, К.4, К.6, К.7, К.9, К.10,К.11 & 9 & 82 \\
\hline & Grup çalışması & К.1, К.2, К.3, К.4, К.5, К.6, К.8, К.9, К.11 & 9 & 82 \\
\hline & Bireysel dinleme & К.1, К.2, К.3, К.5, К.6, К.7, К.8, К.9, К.11 & 9 & 82 \\
\hline & Anlatım yöntemi kullanma & K.1, K.2, K.4, K.8, K.10 & 5 & 45 \\
\hline & $\begin{array}{l}\text { Eserlerin bonasını ve solfejini } \\
\text { yaptırma }\end{array}$ & K.2, K.5, K.7, K.9, K.10 & 5 & 45 \\
\hline \multirow[t]{4}{*}{ Sorunlar } & Öğrenci merkezli & $\begin{array}{l}\text { К.1, К.2, К.3, К.4, К.5, К.6, К.7, К.8, К.9, } \\
\text { К.10, К.11 }\end{array}$ & 11 & 100 \\
\hline & Fiziki şartların yetersizliği & $\begin{array}{l}\text { K.1, K.2, K.3, K.4, K.5, K.6, K.7, K.8, K.10, } \\
\text { K.11 }\end{array}$ & 10 & 91 \\
\hline & Ders saati yetersizliği & К.1, К.2, К.3, К.4, К.5, К.6, К.8, К.10, К.11 & 9 & 82 \\
\hline & Çalg1 yetersizliği & K.3, K.5, K.8 & 3 & 27 \\
\hline \multirow[t]{5}{*}{$\begin{array}{l}\text { Çözüm } \\
\text { önerileri }\end{array}$} & $\begin{array}{l}\text { Bireysel çalgı hocalarından } \\
\text { yardım alma }\end{array}$ & K.1, K.2, K.3, K.4 K.5, K.8, K.9 & 7 & 63 \\
\hline & Teknik çalışmalar yaptırma & К.3, К.4, К.6, К.8, К.10, К.11 & 6 & 54 \\
\hline & $\begin{array}{l}\text { Grup şefleri ve seviye olarak } \\
\text { ileri öğrencilerden yardım } \\
\text { alma }\end{array}$ & K.3, K.5 & 2 & 18 \\
\hline & $\begin{array}{l}\text { Telefon uygulamaları } \\
\text { kullanma }\end{array}$ & K.9, K.10 & 2 & 18 \\
\hline & $\begin{array}{l}\text { Öğrencileri solo performans } \\
\text { ve konserlere teşvik etmek }\end{array}$ & К.5 & 1 & 9 \\
\hline
\end{tabular}

Tablo 4 incelendiğinde kullanılan yöntemler teması altında "gösterip yaptırma", "grup çalışması", "bireysel dinleme", "anlatım yöntemi kullanma", "eserlerin bonasını ve solfejini yaptırma" olmak üzere 5 kod bulunmaktadır. Öğretim elemanlarının özgün ifadelerinden bazı örnekler aşağıdaki gibidir:

K7: Öğrencilerden ara sıra orkestra önünde tek başına çalmalarını talep ediyorum. Bu durum özgüven kazanmalarını da sağlıyor. Sınavlarda kuartet olarak çalmalarını istiyorum. Sınıfta projeksiyon ile eserlerin videolarını izletip dinletiyorum. Deşifre yaptırıyorum.

K8: Çalgısında iyi öğrenciler ile zayıf öğrencileri aynı gruba koyarak eksiklikleri ortadan kaldırmaya çalışıyorum. Ders esnasında anlatım, taklit etme gibi öğretim yöntemleri kullanıyorum. Seçilen repertuvarın zorluk derecesine göre en az iki haftada bir grup çalışması yaptırıyorum ve bireysel olarak da öğrencileri dinliyorum.

K10: Bona çalışmalarına ve vokal uygulamalara yer veriyorum. Bazen eserlerin öykülerinden bahsediyorum. Öğrencilere eser kayıtlarını verip dinlemelerini istiyorum.

Sorunlar teması altında "öğrenci merkezli”, "fiziki şartların yetersizliğiı", "ders saati yetersizliği”, "çalgı yetersizliği” olmak üzere 4 kod bulunmaktadır. Öğretim elemanlarının özgün ifadelerinden bazı örnekler aşağıdaki gibidir:

K3: Ders saatinin yeterli olmaması sebebiyle 4 saate çıkarılması gerektiğini düşünüyorum. Salonun teknik yetersizliği bir yana, çalgı ve araç gereçlerin eksikliğine kadar sıkıntı yaşıyorum. $\mathrm{Bu}$ durum, oluşturmayı hedeflediğim repertuvarı doğrudan etkiliyor.

K7: Genellikle öğrencilerin derse geç gelmeleri sıkıntısını yaşıyorum. Toplu bir şekilde tek ders yapıyoruz ve bir öğrenci gelmediğinde zincirin halkasında kopma oluyor, orkestra tutunamiyor. 2 kemanc1, 2 viyolonselci gelmezse balans direkt bozuluyor. 
K8: Öğrencilerin hazırbulunuşlukları yeterli düzeyde değil. Repertuvarlara ulaşırken bazen güçlük yaşıyorum. İstediğim notasyonu bulamadığım zamanlar oluyor. Teknik donanım konusunda en çok sıkıntı yaşayan bölümlerden biriyiz. Binamızın koridorunda orkestra çalışması yapıyoruz. Derste kullanılan çalgılar fabrikasyon ve düşük seviyeli çalgılar.

Çözüm önerileri teması altında "bireysel çalgı hocalarından yardım alma", "teknik çalışmalar yaptırma", "grup şefleri ve seviye olarak ileri öğrencilerden yardım alma", "telefon uygulamaları kullanma" ve "öğrencileri solo performans ve konserlere teşvik etmek" olmak üzere 5 kod bulunmaktadır. Öğretim elemanlarının özgün ifadelerinden bazı örnekler aşağıdaki gibidir:

K3: Teknik güçlükleri dizi çalışması ve farklı egzersizler ile çözmeye çalışıyorum. Grupla ve bireysel çalışmalar yaptırıyorum. Çalgısında zorlanan öğrencinin yanına çalgı seviyesi iyi bir öğrenciyi koyuyorum. Zaman zaman bireysel çalg1 hocasından düşük seviyeli öğrenciyi çalıştırmasını talep ediyorum.

K5: Grup şefleriyle grup çalışmaları yaptııllarak öğrenci kökenli sorunların giderilmesi için uğraşılmaktadır. Zaman zaman çalgı hocalarından da destek istenmektedir. Öğrencilerin orkestra önünde solo çalma/söyleme davranışları desteklenmelidir. Orkestra konserlerine öğrencilerin izleyici olarak katılmaları sağlanmalıdır. Öğrencilere bir fon veya ödenek vasıtasıyla ülkedeki en iyi orkestraların konserlerini izleme firsatı sağlanabilir.

K9: Whatsapp uygulamasını kullanarak günlük ödevler veriyor ve kendi yaptıkları kayıtları da bana göndermelerini talep ediyorum. Bu yöntem oldukça işe yarıyor. İstenen ödevler bireysel ya da toplu olabiliyor.

Öğretim elemanlarının görüşleri doğrultusunda, dersin uygulama sürecine yönelik farklı sorunlarla karşılaşıldığı söylenebilir. Bunlar; öğrencilerin derse ilgisiz olmaları, devamsızlık yapmaları, derse geç gelmeleri, bireysel çalgılarına yeteri kadar çalışmamaları, çalınacak orkestra eserlerinin deşifresini yapmadan derse hazırlıksız olarak gelmeleri şeklinde sıralanabilir. Öğrenci merkezli bu sorunların dersi olumsuz yönde etkileyerek, bir ürün ortaya koymayı ve ilerleme kaydetmeyi zorlaştırdığı sonucuna ulaşılabilir. Ayrıca öğretim elemanları, orkestra dersinin yürütüldüğü sınıfların akustik ve kapasite bakımından yeterli donanıma sahip olmadığı yönünde görüş bildirmişlerdir. Orkestra çalgıları göz önünde bulundurulduğunda, özellikle yaylı çalgı çalan öğrencilerin rahat hareket edebilecekleri bir alana sahip olmaları gerekmektedir. Bütün bunların yanı sıra öğretim elemanlarının çoğunluğunun orkestra ders saatini yetersiz buldukları görülmektedir. Öğretim elemanlarının bir kısmı da öğrencilerin çalgılarını yetersiz bulduklarını belirtmişlerdir.

Tablo 5: Yay Tekniklerine İlişkin Frekans ve Yüzde Dağılımı

\begin{tabular}{|c|c|c|c|c|c|c|c|c|}
\hline & \multicolumn{2}{|c|}{ Her Zaman } & & \multirow{2}{*}{$\begin{array}{c}\text { S1klıkla } \\
\%\end{array}$} & \multicolumn{2}{|c|}{ Çok Az } & \multicolumn{2}{|c|}{ Kullanmiyorum } \\
\hline Yay Teknikleri & $\mathrm{f}$ & $\%$ & $\mathrm{f}$ & & $\mathrm{f}$ & $\%$ & $\mathrm{f}$ & $\%$ \\
\hline Detaşe & 9 & 82 & 2 & 18 & & & & \\
\hline Legato & 9 & 82 & 2 & 18 & & & & \\
\hline Staccato & 5 & 45 & 4 & 36 & 2 & 18 & & \\
\hline Portato & 4 & 36 & 5 & 45 & 2 & 18 & & \\
\hline Spiccato & 3 & 27 & 3 & 27 & 4 & 36 & 1 & 9 \\
\hline Martele & 3 & 27 & 5 & 45 & 2 & 18 & 1 & 9 \\
\hline Sautille & & & 2 & 18 & 6 & 54 & 3 & 27 \\
\hline Colle & & & & & 5 & 45 & 6 & 54 \\
\hline Saltando & & & & & 5 & 45 & 6 & 54 \\
\hline Pizzicato & 5 & 45 & 5 & 45 & 1 & 9 & & \\
\hline Col Legno Battuo & & & & & 8 & 72 & 3 & 27 \\
\hline Detaşe Porte & 1 & 9 & 2 & 18 & 4 & 36 & 4 & 36 \\
\hline Chopping & & & 1 & 9 & & & 10 & 91 \\
\hline
\end{tabular}


Tablo 5'e göre, saltando, colle, chopping ve col legno tekniklerinin çok nadir, sautille ve spiccato tekniklerinin zaman zaman, martele, staccato ve portato tekniklerinin siklıkla, pizzicato, legato ve detaşe tekniklerinin ise her zaman kullanıldığı söylenebilir.

Tablo 6: Dersin Değerlendirme Sürecine İlişkin Öğretim Elemanı Görüşlerinin Temaları

\begin{tabular}{lllcc}
\hline Temalar & Kodlar & Katılımc1 & f & $\%$ \\
\hline Kullanılan yöntem & Küçük gruplar halinde dinleme & K.3, K.4, K.5, K.6, K.7, K.8, K.9, K.10 & 8 & 73 \\
& Orkestranın tamamını dinleme & K.1, K.2, K.4, K.6, K.8, K.9, K.10 & 7 & 64 \\
& Bireysel dinleme & K.1, K.2, K.3, K.5, K.8, K.9 & 6 & 54 \\
& Çalgı hocaları ile görüşme & K.4, K.6, K.10 & 3 & 27 \\
& Yazıll sınav yapma & K.7 & 1 & 9 \\
Değerlendirme aracı & Ölçek kullanıyorum & K.3, K.4, K.5, K.6, K.7, K.8 & 6 & 54 \\
& Ölçek kullanmıyorum & K.1, K.2, K.9, K.10, K.11 & 5 & 45 \\
\hline
\end{tabular}

Tablo 6 incelendiğinde kullanılan yöntem teması altında "küçük gruplar halinde dinleme", "orkestranın tamamını dinleme", "bireysel dinleme", "çalg1 hocaları ile görüşme", "yazılı sınav yapma" olmak üzere 5 kod bulunmaktadır. Öğretim elemanlarının özgün ifadelerinden bazı örnekler aşağıdaki gibidir:

K7: Orkestra 1'de orkestra yapısı, disiplini, görev dağılımı, orkestranın tarihi (15. yy. ile 20. yy. arasındaki değişimler), orkestradaki çalgılar, ülkemizdeki oda müziği ve orkestra grupları, orkestra dinleme ritüelleri gibi konu başlıklarından teorik bilgiler vererek bu bilgilerden yazılı yapıyorum. Orkestra 2'nin teorik kısmında ulusal ve evrensel orkestralardan ve şeflerden örnekler dinleterek bunları sınavda soruyorum. Orkestra 3 'ün teorik kısmında orkestradaki çalgıların türleri ve ses renklerine göre dinleme ile açıklama çalışmaları yaptırtıyorum. yapıyorum.

K8: Kuartet, bireysel, grup olarak ve hatta orkestranın tamamını dinleyerek değerlendirme

K9: Hem bireysel, hem de gruplar halinde dinliyorum. Sinavlarda değerlendirme yaparken müzikal dinamikler ile duatelere daha çok önem veriyorum.

Değerlendirme aracı teması altında "ölçek kullanıyorum" ve "ölçek kullanmıyorum" olmak üzere 2 kod bulunmaktadır. Öğretim elemanlarının özgün ifadelerinden bazı örnekler aşağıdaki gibidir:

K1: Duatelere uyuyor mu? Entonasyonu, birlikte icras1, yay durumları ve dinamikleri nasıl? Bu sorulara dikkat ediyorum.

K4: Değerlendirme aşamasında, kendime özgü ve bölüm olarak diğer değerlendirme kriterleriyle de örtüşen kendi oluşturduğum bir ölçeğim var. Bu ölçek üç boyuttan oluşuyor; teknik, müzikal ve kişisel(derse devam derse hazırlıklı gelmesi etkinliklere katılım vs.).

K10: Herhangi bir ölçek kullanmıyorum. Fakat öğrencilerin açıkça görebildiği, şeffaf, kendi kriterlerime göre belirlediğim bir puanlama formu kullanıyorum. Öğrencilerin performans değerlendirmelerini bu form üzerinden yaptırıp, görüşlerini alıyorum. 
Tablo 7: Klasik Batı Müziği Eserleri

\begin{tabular}{|c|c|c|c|}
\hline Besteci & Eser & Besteci & Eser \\
\hline W.A.Mozart & 29. Senfoni & W.A.Mozart & Flüt için andante \\
\hline W.A.Mozart & Queen of the night aria & J.C.Bach & Do minör viyola konçertosu \\
\hline G.F.Haendel & Sarabande & G.Faure & Elegie \\
\hline H.Purcell & Rondo & C.Stamitz & $\begin{array}{l}\text { Symphonie konçertant } \\
\text { 1.bölüm }\end{array}$ \\
\hline J.S.Bach & Orchestral suite no:2 & A.Corelli & $\begin{array}{l}\text { Op.6,no.7 concerto grosso, } \\
\text { andante largo, allegro }\end{array}$ \\
\hline A. Vivaldi & $\begin{array}{l}\text { L'estro armonico due violini } \\
\text { concerto }\end{array}$ & W.A.Mozart & $\begin{array}{l}\text { No.21 piyano konçertosu, } \\
\text { andante }\end{array}$ \\
\hline G.Bizet & Carmen suite & F.A.Hoffmaister & Re majör viyola konçertosu \\
\hline J.S.Bach & $\begin{array}{l}\text { Piyano konçertosu, re minör, } 1 . \\
\text { Bölüm "allegro }\end{array}$ & W.A.Mozart & Ave verum corpus \\
\hline A.Dvorak & $\begin{array}{l}\text { 9. Senfoni "yeni dünya senfonisi, } 2 . \\
\text { Bölüm, "largo" }\end{array}$ & P.I.Tschaikovsky & Nocturne \\
\hline A.Vivaldi & La follia op. $1 \mathrm{nr} .12$ & J.S.Bach & Bourree \\
\hline G.Dinicu & Caruta postei - posta arabası & A.Vivaldi & $\begin{array}{l}\text { Concerto for strings rv } 157 \text {, } \\
\text { allegro, largo, allegro }\end{array}$ \\
\hline G.B.Pergolesi & Sicilienne & J.Haydn & Senfoni no. 2 \\
\hline P.I.Tchaikovsky & Danse des petit cygnes & A.Scarlatti & Se tu della mia morte, andante \\
\hline W.A.Mozart & Rondo & G.B.Pergolesi & Stizzoso, mio stizzoso, allegro \\
\hline E.H.Grieg & In the hall of the mountain king & J. Haydn & Symphony nr.39 \\
\hline J.Brahms & Syphonie no: 1 & A.Vivaldi & Concerto grosso rv578 \\
\hline G.Rossini & $\begin{array}{l}\text { Themes from the barber of seville } \\
\text { overture }\end{array}$ & A.Vivaldi & Concerto in rv156 \\
\hline A. Vivaldi & 4 keman için konçerto (op:3 no:10) & J.Haydn & Symphonie nr.44 "trauer" \\
\hline M.Ravel & Pavane & J.Haydn & Symphony hob:1 no:27 in $\mathrm{g}$ \\
\hline Pachabel & Canon & A.Vivaldi & Cello sonata rv40 in e \\
\hline H.Purcell & Rondo & S.Rachmanınoff & Vocalise op.14 no:14 \\
\hline J.Haydn & Kanon & E.Grieg & Peer gynt suite op.46 no: 1 \\
\hline A.Vivaldi & Mevsimler (for seasons) & L.V.Beethoven & Bagatelle \\
\hline J.Haydn & 27. Senfoni & F.Mendelssohn & Tarantella \\
\hline C.Stamitz & Senfoni konçertant & G.Verdi & La donna mobile \\
\hline J.Brahms & Macar dansi 5 & D.Shostakovich & Waltz \\
\hline G.Bizet & Carmen suit & C.Guatelli & Ottoman exhibition march \\
\hline H.Purcell & Overture & B.Bartok & Romen halk danslari \\
\hline A.Vivaldi & Gitar ve orkestra için konçerto rv93 & D.Shostakovich & 2 numarali vals \\
\hline P.I.Tchaikovsky & Russian dance-trepak (nutcracker) & J.Massenet & Cantique \\
\hline Besteci & Eser & Besteci & Eser \\
\hline P.I.Tchaikovsky & March (nutcracker) & C.W.Gluck & Kutsanmış ruhların dansı \\
\hline L.V.Beethoven & Senfoni no:9, senfoni no:5 & P.I.Tchaikovsky & Valse sentimantale \\
\hline G.F.Haendel & Su müziği - air,bourre,hornpipe & E.Grieg & $\begin{array}{l}\text { Two elegiac melodies, } 1 . \\
\text { Heart's wound, 11. Last spring }\end{array}$ \\
\hline
\end{tabular}

Tablo 7 incelendiğinde öğretim elemanlarinin repertuvarlarında en fazla A.Vivaldi'nin (\%14) eserlerine yer verdikleri görülmektedir. Eserleri sıklıkla kullanilan diğer bestecilerin W.A.Mozart (\%9), J. Haydn (\%9), P.I.Tchaikovsky (\%8), J.S.Bach (\%6), H.Purcell ve E.Grieg (\%4) olduğu söylenebilir. Öğretim elemanlarının G.F. Haendel, D.Shostakovich, C.Bizet, C.Stamitz, L.W.Beethoven, G.B.Pergolesi ve J.Brahms'ın (\%3) eserlerini de repertuvarlarına aldıkları söylenebilir. 
Tablo 8: Türk Besteci Eser ve Düzenlemeleri

\begin{tabular}{|c|c|c|c|}
\hline Besteci-Düzenleyen & Eser & Besteci-Düzenleyen & Eser \\
\hline Düz: E. Tuğcular & Gafil Gezme Şaşkın & İ. Taviloğlu & Beşi Bir Yerde \\
\hline Düz: R. Akyürek & Bülbülüm Altın Kafeste & Düz: E. Tuğcular & Kerimoğlu Zeybeği \\
\hline M. Sun & Yedi Cüce & Y. Köse & Küçük Süit \\
\hline $\begin{array}{l}\text { Z. Aydintan, } \\
\text { Düz: S. Bilgin }\end{array}$ & Atam & $\begin{array}{l}\text { Z. Arca, Çoks: Mansur } \\
\text { Özen, Düz: Y. Kıvrak }\end{array}$ & Dertli Kaval \\
\hline $\begin{array}{l}\text { F. Canselen, } \\
\text { Düz: Y. Kıvrak }\end{array}$ & İzindeyiz & Düz: E. Bayraktar & $\begin{array}{l}\text { Çamdan Sakız } \\
\text { Akıyor }\end{array}$ \\
\hline M. Sun & Biz Atatürk Gençleriyiz & $\begin{array}{l}\text { C. R. Rey, Düz: E. } \\
\text { Tuğcular }\end{array}$ & Gemiler \\
\hline C. Akın, Düz: S. Bilgin & Bozkırlar Yeşerecek & C. R. Rey, Düz: S. Bilgin & 10.Y1l Marş1 \\
\hline $\begin{array}{l}\text { Y. Kıvrak, Düz: S. } \\
\text { Bilgin }\end{array}$ & Şanlı Atatürk & Düz: E. Tuğcular & Ağasar'ın Balı \\
\hline $\begin{array}{l}\text { Kaptanzade Ali Rıza } \\
\text { Bey, Düz: R.Akyürek }\end{array}$ & Efem & Düz: O. Balc1 & Kadifeden Kesesi \\
\hline R. Fersan & Rast Peşrev & Y. Tura & Gül Yine Sen \\
\hline A. S. Ece & Masal & Düz: S. Bilgin & Çalın Davulları \\
\hline N. Kodallı & Telli Turna Suiti & Düz: N. Yıldız & $\begin{array}{l}\text { Ceviz Oynamaya } \\
\text { Geldim }\end{array}$ \\
\hline Ş. Alıcıoğlu & Bir Elveda Şarkısı & $\begin{array}{l}\text { Kaptanzade Ali Riza Bey, } \\
\text { Düz: O. Balcı }\end{array}$ & $\begin{array}{l}\text { Denizde Aksam, } \\
\text { Andante, Allegro }\end{array}$ \\
\hline Düz: H. Keskin & $\begin{array}{l}\text { İki Türkü, "Oy Trabzon } \\
\text { Trabzon, Batum Türküsü" }\end{array}$ & Düz: H. T. Kılıç & Sar1 Gelin \\
\hline Düz: H. T. Kılıç & $\begin{array}{l}\text { Cezayirin Harmanları - } \\
\text { Bursa Yöresi } \\
\text { Mevlam Bir Çok Dert }\end{array}$ & Düz: H.T. Kılıç & Vardar Ovas1 \\
\hline Düz: K. Karkın & $\begin{array}{l}\text { Vermiş - Türkü / Yöre: } \\
\text { Malatya }\end{array}$ & M. Sun, Düz: A. Özbay & Seni Sevdim Diye \\
\hline $\begin{array}{l}\text { Santuri Ethem Efendi, } \\
\text { Düz: O. Balcı }\end{array}$ & Şehnaz Longa & E. Tuğcular & $\begin{array}{l}\text { Renkler Süiti, } \\
\text { Köroğlu }\end{array}$ \\
\hline A. Sevgi & Nikriz & $\begin{array}{l}\text { Kemani Kevser Hanım, } \\
\text { Düz: O. Balcı }\end{array}$ & Nihavend Longa \\
\hline Düz: A. S. Ece & Ben Seni Sevdiğimi & Düz: M. Özdemir & Tango Potpuri \\
\hline $\begin{array}{l}\text { Dede Efendi, Düz: O. } \\
\text { Balcı }\end{array}$ & Gülnihal & Düz: E. Tuğcular & Üç Türkü, \\
\hline H. Özçivi & Nihavend Sirto & Düz: Ç. Aytepe & $\begin{array}{l}\text { Bahçalarda Mor } \\
\text { Meni }\end{array}$ \\
\hline E. Tuğcular & Çiğdem & İ. İnci & Aşalım \\
\hline Düz: E. Tuğcular & Osmanım & $\begin{array}{l}\text { Kaptanzade Ali Riza Bey, } \\
\text { Düz: O.Balcı }\end{array}$ & Denizde Akşam \\
\hline
\end{tabular}

Tablo 8 incelendiğinde öğretim elemanlarının repertuvarlarında, E.Tuğcular'ın bestelerine (\%4), yine E. Tuğcular'ın düzenlemelerine (\%12), O. Balcı'nın düzenlemelerine (\%12) ve S.Bilgin'in düzenlemelerine (\%10) yer verdikleri söylenebilir. Öğretim elemanlarının çalışılan repertuvarlarda Kaptanzade Ali Riza Bey ve M. Sun'un bestelerine (\%6), Y. Kivrak ve A. S. Ece'nin beste (\%2) ve düzenlemelerine (\%4), C. R. Rey'in bestelerine (\%4) siklıkla yer verdikleri görülmektedir. H.T.Kılıç (\%6) ve R. Akyürek'in (\%4) düzenlemeleri de çalışılan eserler arasında bulunmaktadır. Orkestra repertuvarlarına bakıldığında derse giren öğretim elemanlarının kendilerine ait düzenlemelere de yer verdikleri görülmektedir. 
Tablo 9: Eser Albümleri

\begin{tabular}{ll}
\hline Yazar & Kitap/Albüm \\
\hline Manookian & Album of Overture Themes \\
A. S. Ece & Gençlik Orkestraları İçin Halk Ezgileri \\
Z. Çubuk, H. T. Kılıç & Orkestra ve Oda Müziği Eserleri \\
U. Türkmen & Birlikte Söyleme ve Çalma İçin Dağarcık Demet \\
E. Tuğcular & Orkestra ve Oda Müziği Eserleri \\
S. Bilgin & Orkestra Albümü \\
A. Albuz & Orkestra ve Oda Müziği Eserleri \\
M. Dedeoğlu & Orkestra İçin 5 Parça - Andantino, Allegretto \\
\hline
\end{tabular}

Tablo 9'da elde edilen veriler doğrultusunda öğretim elemanlarının 8 albümden yararlandıkları söyelenebilir. 7 albümün Türk, 1 albümün ise yabancı yazar tarafından hazırlandığı görülmektedir.

Tablo 10: Popüler Müzikler ve Film-Dizi Müzikleri

\begin{tabular}{|c|c|c|c|}
\hline Besteci - Düzenleyen & Eser & Besteci - Düzenleyen & Eser \\
\hline C.Velazquez & Besame Mucho & $\begin{array}{l}\text { R.Henderson / M.Dixon, } \\
\text { Düz: M. E. Özdemir }\end{array}$ & Bye Bye Blackbird \\
\hline G.Bregovic & Underground Tango & $\begin{array}{l}\text { J.Kander / F.ebb, Düz: } \\
\text { M.E.Özdemir }\end{array}$ & New York New York \\
\hline $\begin{array}{l}\text { J.Williams, Düz: } \\
\text { C.jones }\end{array}$ & Schindler's List & F.Vall, Düz: M.ergül & $\begin{array}{l}\text { Can’t Take My Eyes } \\
\text { Off You }\end{array}$ \\
\hline Düz: C.Terry & $\begin{array}{l}\text { Jingle Bells - } \\
\text { Traditional Music }\end{array}$ & $\begin{array}{l}\text { Sumner / Clapton / Kamen, } \\
\text { Düz: C.incemen }\end{array}$ & It's Probably Me \\
\hline P.E.Fletcher & Folk Tune & $\begin{array}{l}\text { A.Hammond / J.Bettis, } \\
\text { Düz: M.E.Özdemir }\end{array}$ & One Moment in Time \\
\hline L.Rago & Intermezzo & $\begin{array}{l}\text { Bon Jovi / Sambora / Martın, } \\
\text { Düz: M.E.Özdemir }\end{array}$ & It's My Life \\
\hline G.A.Speckert & Pizz-a- Tango & R.Falvo & Dicitencello Vuie \\
\hline $\begin{array}{l}\text { L.Einaud,, Düz: } \\
\text { S.Canyakan }\end{array}$ & Primavera & K.Jenkıns & Adiemus \\
\hline $\begin{array}{l}\text { Adele / P.Eqworth, } \\
\text { Düz: G.çetin }\end{array}$ & Skyfall & J.Lennon, P.Mccartney & Hey Jude \\
\hline $\begin{array}{l}\text { A.Ketelbey, Uyar: } \\
\text { Ç.şen }\end{array}$ & In a Persian Market & Anonim, düz: B. Krogstad & $\begin{array}{l}\text { The Water is Wide, } \\
\text { Andante }\end{array}$ \\
\hline $\begin{array}{l}\text { S.Aksu / O.Tunç, } \\
\text { Uyar: A.Kırşan }\end{array}$ & 1945 & Coldplay & Viva La Vida, Allegro \\
\hline K.Badelt & Karayip Korsanları & G.Vardapet & $\begin{array}{l}\text { Miniatures, The Red } \\
\text { Shawl, Stalk Along }\end{array}$ \\
\hline R. Djawadı & Game of Thrones & $\begin{array}{l}\text { E. Morıconne, Düz: B. } \\
\text { Krogstad }\end{array}$ & Cinema Paradiso \\
\hline C.R.jepsen & Call me Maybe & F. Loewe & $\begin{array}{l}\text { I Coluld Have Dance } \\
\text { All Night }\end{array}$ \\
\hline D.Elfman & $\begin{array}{l}\text { Themes From Edward } \\
\text { Scissorhands }\end{array}$ & M. Mores \& The Police & Roxanne \\
\hline Besteci - Düzenleyen & Eser & Besteci - Düzenleyen & Eser \\
\hline J.Myers & Cavatina & L.Anderson & Jazz Pizzicato \\
\hline Queen-B.May & $\begin{array}{l}\text { The Show Must Go } \\
\text { On }\end{array}$ & A.Piazzola & Finale \\
\hline $\begin{array}{l}\text { F.Rosell1, Uyar: } \\
\text { E.Okay }\end{array}$ & Kutsal Gece & K.Kondo & Super Mario Bros \\
\hline L. Mairhofer & Rock For Fun & L. Gaga & Hit Mix \\
\hline Queen & I Want it All & M.Giachinno, Düz: S.Bulla & Ratatouille \\
\hline J. Hassreiter, Düz: & Dancing Show & A.G.Villodo & El Choclo - Tango \\
\hline
\end{tabular}


M.E.Özdemir

A.Newley /

L.Bricusse,

Düz: M.E.Özdemir

G.d.Weiss / B.Thiele,

Düz: M. Ergül
Feeling Good

P.Desmond

Criollo

Take Five

Tablo 10 incelendiğinde öğretim elemanlarının farklı türlerden örneklere, repertuvarlarında yer verdikleri görülmektedir. Film müziklerinden, Karayip Korsanları, Game of Thrones, Schindler's List gibi örneklere rastlanmaktadır. Farklı türden eserlerin orkestra dersi repertuvarında yer almasının bu dersi öğrenciler için daha eğlenceli hale getireceği, ayrıca dinleyiciler üzerinde de olumlu etkileri olacağı düşünülmektedir.

\section{Tartışma ve Sonuç}

Araştırmada elde edilen bulgular doğrultusunda, Orkestra/Oda Müziği dersi öğretim elemanlarının repertuvar oluştururken öğrencilerin hazırbulunuşluk düzeylerine, repertuvarın niteliğine, yapılacak olan konser ile etkinliklerin amaç ve hedeflerine dikkat ettikleri sonucuna ulaşılmıştır. Öğretim elemanlarının dinleyiciler tarafindan beğeni kazanacak eserleri seçerek repertuvar oluşturmaya çalıştıkları ve kültürel değerleri göz önünde bulundurdukları da ulaşılan bir diğer sonuçtur. Bu sonuçlar; Varış (2007)'ın “Eğitim Fakülteleri Müzik Eğitimi Anabilim Dalları Orkestra ve Yönetimi Dersi Öğretim Sürecinin Betimlenmesi ve Değerlendirilmesi”, Akyürek'in (2009) "Müzik Eğitimcisi Yetiştiren Kurumlarda Orkestra/Oda Müziği Eğitimi ve Orkestra Yapılanmalarının İncelenmesi” ve Soytok'un (2017) "Müzik Eğitimi Anabilim Dallarındaki Flütlü Oda Müziği Gruplarında Karşılaşılan Sorunlar" başlıklı araştırmalarından elde edilen sonuçlar ile benzerlik göstermektedir. Varış (2007) ve Akyürek (2009) öğrencilerin bireysel çalgılarındaki performans ve teknik düzey farklılıklarının dikkate alınarak dersin amacına uygun ders planı hazırlanması gerektiğini vurgulamıştır. Soytok (2017) ise "öğretim elemanlarının oda müziği dersinin eğitsel amaçları dışında, o şehrin kültürel beklentilerini karşılama gibi bir sorumluluklarının da olduğunu ve bu durumun seçilecek repertuvara etki ettiğini” araştırmasının sonuçlarında belirtmiştir.

Öğretim elemanlarının, çalıştırılacak eserleri planlarken kaynak yetersizliği yaşamaları, öğrencilerin çalgılarının kalitelerinin düşük olması ve çalgıların orkestra içindeki dağılımlarının dengesiz olması gibi sorunlarla karşılaştıkları görülmüştür. Öğretim elemanlarının çalıştırmak istedikleri eserlerin orkestra düzenlemelerine bazen ulaşamadıkları, yazılı kaynakları yetersiz buldukları ve notasına ulaştıkları kimi eserleri de öğrenci seviyelerine uygun bulmadıkları ulaşılan diğer sonuçlar arasındadır. Orkestrada yer alan öğrencilerin seviyelerindeki farklılıklardan ve çalg1 dağılımındaki dengesizlikten dolayı teknik açıdan zor eserlerin repertuvara alınamadığı ise tespit edilen bir diğer sonuçtur. Bu durumların öğretim elemanlarını eser seçimi aşamasında zorladığı belirlenmiştir.

Öğretim elemanlarının, eğitim-öğretim sürecinde öğrencilerin derslere zamanında gelmemesi, hazırbulunuşluk düzeylerinin yeterli olmaması, fiziki şartların yetersizliği ve ders saatlerinin az olması gibi sorunlarla karşılaştıkları görülmüştür. Ayrıca orkestrada yer alan öğrencilerin fiziki olarak düşük kalitede fabrikasyon çalgılara sahip olmasından ve öğrencilerin orkestra dersine yeteri kadar ilgi göstermemesinden kaynaklanan sorunların da olduğu belirlenmiştir. Bu sonuçlar Öz (2001)'ün "Müzik Öğretmeni Yetiştiren Kurumlarda Orkestra/Oda Müziği Eğitiminde Yaylı Çalgıların Yeri ve Önemi” başlıklı çalışmasındaki müzik eğitimi bölümlerinde araç-gereç, repertuvar eksikliği sorunlarının yaşanması ve Akyürek'in (2009) "Müzik Eğitimcisi Yetiştiren Kurumlarda Orkestra/Oda Müziği Eğitimi ve Orkestra Yapılanmalarının İncelenmesi” isimli araştırmasındaki orkestra/oda müziği haftalık ders saatinin yetersiz olması sonuçları ile örtüşmektedir. Köse ve Çiftçibaşı (2016) "Koro ve Orkestra/Oda Müziğinde Seslendirme/Yorumlama Başarım Gücü Üzerine Program Odaklı Bir İnceleme" isimli 
araştırmalarında ders saatinin yeterli olmadığını ve öğretim elemanlarının başarım gücünü artırmak için ekstra çalışmalar yaptıklarını belirtmişlerdir.

Orkestra eğitimi sürecinde öğrencilerden kaynaklanan sorunların çözümü için öğretim elemanlarının bireysel çalgı öğretim elemanları ile işbirliğine gittikleri ve bireysel çalgı öğretim elemanlarından bu konuda yardım talep ettikleri sonuçlarına ulaşılmıştır. Bazı öğretim elemanlarının telefon uygulamalarını (WhatsApp vb.) kullandıkları, ödev ve günlük çalışma takibini bu uygulamalar ile gerçekleştirdikleri ve bir akademisyenin de öğrencileri solo performans ve konserlere teşvik ettiği ulaşılan diğer sonuçlar arasındadır.

En sık kullanılan öğretim yöntemlerinin sırasıyla, gösterip yaptırma, grup çalışması ve bireysel dinleme yöntemi olduğu tespit edilmiştir. Bu üç yöntem de çalg1 ve orkestra eğitiminde en çok kullanılan, verim sağlanan ve orkestra dersi hedef kazanımlarının gerçekleştirilmesi için önemli olduğu öngörülen yöntemlerdir.

Öğretim elemanları derslerde sağ el tekniklerinden detaşe, legato, pizzicato tekniklerinin her zaman, staccato, portato, martele tekniklerinin sıklıkla, spiccato, sautille tekniklerinin kısmen, colle, saltando, detaşe porte, col legno battuo ve chopping tekniklerinin ise çok nadir kullanıldığını belirtmişlerdir.

Değerlendirme aşamasında öğretim elemanlarının bir kısmının ölçek kullandığı tespit edilmiştir. Ölçek kullanmayan öğretim elemanları ise kendilerine ait (derse devam, gözlem formu, 1 dakikada akort vb.) farklı kriterler doğrultusunda değerlendirmeler yaptıklarını belirtmişlerdir. Ulaşılan bulgular doğrultusunda öğretim elemanlarının değerlendirme ile ilgili olarak bireysel, küçük gruplar halinde ve orkestranın tamamını dinleme yöntemlerini kullandıkları tespit edilmiştir. Değerlendirme sürecinde, diğer çalgı hocaları ile görüşen ve yazılı sınav yapan öğretim elemanlarının da olduğu görülmüştür.

Orkestra/oda müziği dersinde çalışılan eserlerin tür ve dönemlerinde farklılıklar olduğu görülmektedir. Klasik müzik bestecilerinden en fazla A.Vivaldi'nin eserlerine yer verildiği, eserleri çoğunlukla kullanılan diğer bestecilerin E.Grieg, H.Purcell, J.S.Bach, W.A.Mozart, J.Haydn ve P.I.Tchaikovsky olduğu sonuçlarına ulaşılmıştır. Şen vd. (2019)'de gerçekleştirdikleri araştırmalarında müzik eğitim anabilim dalı orkestralarında en çok eseri seslendirilen bestecinin A. Vivaldi olduğunu belirtmişlerdir. Bu sonuç varolan araştırmanın sonucu ile örtüşmektedir. Türk bestecilerinin eserlerinin ve Türk müziği eserlerinin çok sesli düzenlemelerinin de orkestra/oda müziği derslerinde sıklıkla kullanıldığı tespit edilmiştir. E. Tuğcular'ın bestelerinin ve düzenlemelerinin, O. Balcı'nın ise düzenlemelerinin çoğunlukla çalıştırıldığı görülmüştür. Bu eserlerin yanı sıra popüler müzik ile film-dizi müziği gibi müzik türlerinin de orkestra/oda müziği dersinde kullanıldığı tespit edilmiştir.

\section{Öneriler}

- Müzik öğretmeni yetiştiren kurumlardaki çalg1 seçimleri, orkestrayı oluşturan çalg1 gruplarının sayısal dengesi göz önünde bulundurularak yapılabilir.

- Müzik öğretmeni yetiştiren kurumlardaki öğrenci orkestraları için düzeye uygun eser ve düzenlemelerin sayısı arttırılarak yazılı kaynakların zenginleştirilmesi sağlanabilir.

- Müzik öğretmeni yetiştiren kurumlarda, orkestra/oda müziği dersine destek oluşturması bakımından, bireysel çalgı hocaları ile işbirliği yapılarak, öğrencilerin teknik zorlukların üstesinden daha kolay gelmesi sağlanabilir.

- Müzik öğretmeni yetiştiren kurumlarda orkestra çalışma alanları, fiziki olarak iyileştirilebilir. 
- Müzik öğretmeni yetiştiren kurumlarda sadece orkestra/oda müziği dersi için orkestra dersliklerinin oluşturulması sağlanabilir.

- Müzik öğretmeni yetiştiren kurumlara nitelikli çalgıların demirbaş olarak alınarak, maddi durumu iyi olmayan öğrencilerin bu çalgılardan faydalanması sağlanabilir.

- Müzik öğretmeni yetiştiren kurumlarda orkestra/oda müziği dersinin haftalık ders saati arttır1labilir.

- Müzik öğretmeni yetiştiren kurumlarda bireysel çalg1 dersinin haftalık ders saati arttırılabilir.

- Müzik öğretmeni yetiştiren kurumlardaki orkestra/oda müziği dersine yönelik araştırmaların arttırılarak ilgili alanyazına katkısı sağlanabilir.

\section{Kaynakça}

Akyürek, R. (2009). Müzik eğitimcisi yetiştiren kurumlarda orkestra/oda müziği eğitimi ve orkestra yapılanmalarınin incelenmesi. Doktora tezi, Abant İzzet Baysal Üniversitesi Sosyal Bilimler Enstitüsü.

Akyürek, R. (2018). Müzik eğitimcisi yetiştiren kurumlarda orkestra/oda müziği eğitimi etkinlik sürecinin incelenmesi. Turkish Studies Educational Sciences 13(19), 6576. http://dx.doi.org/10.7827/TurkishStudies.14034

Büyüköztürk, Ş. \& Çakmak E.K. \& Akgün, Ö.E. \& Karadeniz, Ş. \& Demirel, F. (2009) Bilimsel Araştırma Yöntemleri (3. Baskl). Pegem Akademi.

Delikara, A. (2017). Yaylı çalgı ögrencilerinin orkestra/oda müziği dersine ilişkin görüşleri. 1. Uluslararası İpekyolu Akademik Çalışmalar Sempozyumu.

Karasar, N. (2014). Bilimsel araştırma yöntemi (27 Basım). Nobel Akademik Yayıncılık.

Karasar, N. (2009) Bilimsel araştırma yöntemi (20. Basım). Nobel Yayın Dağıtım.

Kıvrak, Y. (2003). Müzik ögretmeni yetiştiren kurumlarımızda toplu çalma/söyleme derslerindeki repertuar sorunu. Cumhuriyetimizin 80. Y1lında Müzik Sempozyumu.

Köse, H.S. \& Çiftçibaşı, M.C. (2016). Koro ve orkestra/oda müziğinde seslendirme/yorumlama başarım gücü üzerine program odaklı bir inceleme. Mehmet Akif Ersoy Üniversitesi, Sosyal Bilimler Enstitüsü Dergisi, 8 (17), 293-306.

Öz, N.B. (2001). Müzik öğretmeni yetiştiren kurumlarda orkestra/oda müziği eğitiminde yaylı çalgıların yeri ve önemi, Uludağ Üniversitesi Ĕ̈itim Fakültesi Dergisi, 14 (1), 93-99.

Özeke, S. (2003). A history of music education in the republic of Turkey, 1982-1998. Doktora Tezi, Arizona State University.

Soytok, S. (2017). Müzik eğitimi anabilim dallarındaki flütlü oda müziği gruplarında karşılaşılan sorunlar, Afyon Kocatepe Üniversitesi, Akademik Müzik Araştırmaları Dergisi,3(5): 1-16. https://doi.org/10.5578/amrj.29172

Şen, Ç. \& Şen E. \& Kurtaslan Z. \& Aydın B. (2019). Müzik eğitimi anabilim dallarında orkestra/oda müziği dersi kapsamında hazırlanan konser repertuvarlarının incelenmesi, Ekev Akademi Dergisi, 23(79): 69-82. http://dx.doi.org/10.17753/Ekev1155

Türkmen, U. (2006). Mesleki müzik okullarındaki orkestra derslerinde orkestra düzenlemeleri yapılmış halk ezgilerinin kullanılabilirliğine yönelik öğretmen ve öğrenci tutumları. Afyon Kocatepe Üniversitesi Sosyal Bilimler Dergisi, 8(2): 371-400. 
Uçan, A. (1994). Müzik eğitimi, Müzik Ansiklopedisi Yayınları.

Varış, Y.A. (2007). Eğitim fakülteleri müzik eğitimi anabilim dalları orkestra ve yönetimi dersi ögretim sürecinin betimlenmesi ve değerlendirilmesi. Doktora Tezi, Gazi Üniversitesi Eğitim Bilimleri Enstitüsü.

Yener, Ö. (2006). Muammer Sun'un Yaşamı ve Eğitim Müziğine Katkıları, Yüksek Lisans Tezi, Dokuz Eylül Üniversitesi Eğitim Bilimleri Enstitüsü.

Yıldırım, A. \& Şimşek H. (2006). Sosyal bilimlerde nitel araştırma yöntemleri, Seçkin Yayınları.

Yükseköğretim Kurulu (1998). Eğitim fakülteleri ögretmen yetiştirme lisans programlar, Mart, Ankara.

Yükseköğretim Kurulu (2007). Öğretmen yetiştirme ve eğitim fakülteleri(1982-2007),Temmuz, Ankara.

Yükseköğretim Kurulu (2018). Müzik öğretmenliği lisans programı. 